\title{
Downregulation of the long non-coding RNA XLOC_010588 inhibits the invasion and migration of colorectal cancer
}

\author{
YUE LI $^{1}$, LIN ZHAO $^{2}$, YINING ZHANG $^{1}$, LIN GUAN $^{1}$, HUIJING ZHANG $^{3}$, \\ HUAN ZHOU ${ }^{3}$, TONG GAO ${ }^{1}$, PENG MIAO ${ }^{4}$ and MINGJUN SUN ${ }^{1}$ \\ ${ }^{1}$ Department of Gastroenterology, The First Hospital of China Medical University, Shenyang, Liaoning 110001; \\ ${ }^{2}$ Department of Pharmacology, School of Pharmaceutical Sciences, China Medical University, \\ Shenyang, Liaoning 110122; Departments of ${ }^{3}$ Endoscopy and ${ }^{4}$ Anal and Intestinal Surgery, \\ The First Hospital of China Medical University, Shenyang, Liaoning 110001, P.R. China
}

Received June 16, 2017; Accepted February 7, 2018

DOI: $10.3892 /$ or.2018.6260

\begin{abstract}
Long non-coding RNAs (IncRNAs) have emerged as major players in many biological and pathological processes; however, investigation into the function of lncRNAs in the development and progression of cancer is in its infancy. Therefore, clarification of the mechanism by which cancer-related lncRNAs function is of critical importance in research on tumorigenesis. It has been demonstrated that the lncRNA XLOC_010588 is expressed at a low level in cervical cancer, and that this has significant impact on the proliferation of cervical cancer cells. However, the expression pattern and functional roles of XLOC_010588 in colorectal cancer (CRC) remain unclear. In the present study, it was demonstrated that the expression of XLOC_010588 was significantly higher in CRC tissues when compared with that in adjacent normal tissues, and that XLOC_010588 was closely associated with metastasis and poor prognosis, thus indicating that XLOC_010588 may function as an oncogene. Additionally, downregulation of XLOC_010588 expression markedly inhibited the invasion and migration of CRC cells. Furthermore, it was demonstrated that XLOC_010588 may regulate the progression of CRC via the epithelial-mesenchymal transition (EMT) pathway. Notably, downregulation of XLOC_010588 inhibited the invasion and migration of CRC cells by regulating genes associated with EMT. Our findings revealed that XLOC_010588 may be considered as a novel potential diagnostic biomarker in CRC.
\end{abstract}

Correspondence to: Professor Mingjun Sun, Department of Gastroenterology, The First Hospital of China Medical University, 155 Nanjingbei Road, Shenyang, Liaoning 110001, P.R. China

E-mail: sunmjmw@163.com

Key words: colorectal cancer, long non-coding RNA, XLOC_010588, invasion, migration, epithelial-mesenchymal transition

\section{Introduction}

Colorectal cancer (CRC), which ranks third in terms of cancer-related morbidity and second in terms of cancer-related mortality worldwide, is considered a major threat to public health $(1,2)$. Colorectal carcinogenesis is a multi-step biological process involving dysregulation of multiple oncogenes and tumor suppressor genes (3). Despite recent progress in diagnostic techniques and highly effective medical treatments, the overall survival rate of patients with CRC remains relatively low (4). At present, in light of the growing incidence rate and poor prognosis of $\mathrm{CRC}$, there is an urgent demand to understand the specific molecular mechanisms underlying the pathogenic process of CRC, as this may facilitate the development of effective therapeutic strategies to ultimately improve patient prognosis $(5,6)$.

The high mortality rate associated with CRC is generally attributed to tumor invasion and metastasis. There are many factors and systems that are related to tumor invasion and metastasis, including the epithelial-mesenchymal transition (EMT), which promotes cancer cell invasion and migration. Specifically, EMT promotes epithelial cells in a certain region to detach from epithelial tissue and migrate to other locations, which is the basis of tumor metastasis in tumorigenesis. Therefore, inhibition of EMT may effectively control the migration of tumor cells. Recent studies have revealed that EMT may be regulated by non-coding RNAs (ncRNAs) as well as coding RNAs; however, data on the function of ncRNA in EMT remains limited $(7,8)$.

To date, improvements in whole-genome and transcriptome sequencing technologies have led to the discovery that the majority of the full mammalian genome can be transcribed; however, most of the transcripts have limited or no protein-coding capacity, and are known as ncRNAs $(9,10)$. Distinct from small ncRNAs (such as siRNAs, miRNAs and piRNAs) that have been widely studied, long non-coding RNAs (IncRNAs) are obscure molecules that make up 80\% of ncRNAs and have unclear functions at present (9). IncRNAs, which are transcripts of $>200$ nucleotides in length, are transcribed by RNA polymerase II (RNAPII); however, they have few or no open reading frames (ORFs). Extensive evidence 
suggests that lncRNAs serve crucial roles in a wide variety of fundamental biological processes, including embryonic development, epigenetic silencing, transcriptional and translational control, cell growth, cell differentiation, cell migration and tumorigenesis $(11,12)$. Additionally, extensive research has provided strong evidence to suggest that lncRNAs serve a functional role in a range of human diseases, including various types of cancer, such as breast (13), pancreatic (14), lung (15), gastric (10) and cervical (16). Furthermore, it has been ascertained that numerous lncRNAs participate in both oncogenic and tumor-suppressing pathways in tumorigenesis $(10,17,18)$. For instance, lncRNA MVIH may serve as an oncogene, serving to promote cell proliferation and invasion and indicating poor prognosis of non-small cell lung cancer (11). Similarly, lncRNA GPR158-AS1 has been associated with high tumor risk, while 1ncRNA KCNK15-AS1 has been shown to be protective against non-small cell lung cancer (19). Recently, evidence has suggested that various lncRNAs also act as modulators in the carcinogenesis and progression of human CRC, thus indicating their potential as novel therapeutic targets. Regarding CRC, research on the molecular and biological functions of lncRNAs in CRC is still in its infancy, and has so far had limited success in elucidating the specific molecular mechanisms. However, previous studies indicated that lncRNAs may be potential biomarkers for the diagnosis and treatment of CRC $(11,20,21)$.

In the present study, we first determined that the expression of XLOC_010588 was higher in cancer tissues compared with that in adjacent normal tissues in CRC patients, and that XLOC_010588 was closely associated with metastasis and poor prognosis. Further functional experiments revealed that XLOC_010588 promoted cell invasion and migration. In addition, we demonstrated that downregulation of XLOC_010588 may regulate the progression of $\mathrm{CRC}$ invasion and migration via the EMT pathway. In summary, our findings demonstrated that XLOC_010588 may serve as an oncogene in CRC invasion and metastasis.

\section{Materials and methods}

Ethics statement. In the present study, all tissue microarrays were purchased from Shanghai Outdo Biotech Co., Ltd. (Shanghai, China), and were approved by the local Ethics Committee (Zhejiang Taizhou Hospital Ethics Committee, Zhejiang Taizhou Hospital, Zhejiang, China). Due to the retrospective nature of the study, the Ethics Committee waived the requirement for written informed consent from the patients. All the samples were anonymized.

Tissue preparation. A total of 111 samples of cancer tissue and 70 samples of normal adjacent tissues isolated from CRC patients were purchased from Shanghai Outdo Biotech Co., Ltd. The tissues supplied by Shanghai Outdo Biotech Co., Ltd., were collected during surgery from November 2009 to May 2010, and the longest follow-up time of the tissue samples was 68 months, and the shortest follow-up time was only 1 month. Comprehensive clinicopathological data on the tissue samples, including patient age and sex, tumor size, differentiation and $\mathrm{T}$ stage, and presence of lymph node metastasis and distant metastasis, were also collected.
In situ hybridization (ISH). XLOC_010588 expression was detected by ISH in the cancer tissues and normal adjacent tissues of CRC patients. Following dewaxing of the microarray sections, we applied an Enhanced Sensitive ISH Detection kit II (AP) (Boster Biological Technology, Ltd., Wuhan, China). Following completion of the prehybridization, digoxigenin-labeled oligonucleotide probes (DIG-5' ATTCTAACA TAATATCCCTGCAGT 3'-DIG) were hybridized at $40^{\circ} \mathrm{C}$ overnight, and then the kit was used according to the manufacturer's instructions. Based on both the intensity and proportion of XLOC_010588-positive cells, the staining scores were determined using a relatively simple, reproducible scoring method. On a scale of 0-3, the staining intensity was scored as follows: 0 , none; 1 , weak; 2 , medium; and 3 , strong. The extent of staining was scored on a scale of $0-100 \%$. The product of the staining intensity and staining extent scores was used as the final score for XLOC_010588 staining, with the final staining scores ranging from 0 to 300 (22). The average score of each sample was used to assess cutoff scores for XLOC_010588 overexpression using receiver operating characteristic (ROC) curves (23).

Cell lines. The human CRC cell lines Caco-2, HT-29, SW480, SW620 and HCT116, as well as normal human intestinal epithelial cells (HIEC-6), were obtained from the Cell Bank of Type Culture Collection of the Chinese Academy of Sciences (Shanghai, China). The HIECs were cultured in Dulbecco's modified Eagle's medium (DMEM; HyClone Laboratories; GE Healthcare Life Sciences, Logan, UT, USA); the Caco-2, HT29 and HCT116 cell lines were cultured in RPMI-1640 medium (HyClone Laboratories; GE Healthcare Life Sciences); and the SW480 and SW620 cell lines were cultured in Leibovitz's L-15 medium (Gibco Cell Culture; Gibco; Thermo Fisher Scientific, Inc., Waltham, MA, USA). All media were supplemented with $10 \%$ fetal bovine serum (FBS) and $100 \mathrm{U} / \mathrm{ml}$ penicillin/streptomycin (both from HyClone Laboratories; GE Healthcare Life Sciences). All cell lines were maintained in a humidified chamber containing $5 \% \mathrm{CO}_{2}$ at $37^{\circ} \mathrm{C}$.

RNA extraction and RT-qPCR analysis. Total RNA was extracted from human CRC cell lines using TRIzol reagent (Invitrogen; Thermo Fisher Scientific, Inc.) according to the manufacturer's instructions, and then reverse transcribed into cDNA with a PrimeScript RT Reagent kit with gDNA Eraser (Perfect Real-Time) (Takara Bio, Inc., Otsu, Japan). The primer sequences were as follows: XLOC_010588 forward, 5'-TGTG AAGAGGAGAACATAAAAGG-3' and reverse, 5'-AAGCAA GATAATACAGTGGCGA-3'; and GAPDH forward, 5'-CTCC TCCTGTTCGACAGTCAGC-3' and reverse, 5'-CCCAATAC GACCAAATCCGTT-3'. The target cDNA was amplified in a 10- $\mu$ l reaction mixture containing SYBR Premix Ex Taq II (Takara Bio, Inc.), which was completed on an ABI 7500 Real-Time PCR system (Thermo Fisher Scientific, Inc.). The amplification profile was $95^{\circ} \mathrm{C}$ for $5 \mathrm{~min}$, followed by 42 cycles of denaturation at $95^{\circ} \mathrm{C}$ for $15 \mathrm{sec}$, and annealing and extension at $60^{\circ} \mathrm{C}$ for $60 \mathrm{sec}$. All experiments were performed in triplicate. Relative gene expression was determined using the comparative delta-delta $\mathrm{Cq}$ method (2- $\Delta \Delta \mathrm{Cq})(17)$. GAPDH was used as an internal control for normalization. 
Transfection. Based on the expression of XLOC_010588 in the CRC cell lines, SW620 cells were selected for a knockdown study and HCT116 cells for an overexpression experiment.

To achieve knockdown of XLOC_010588, after being seeded into 6-well plates and incubated overnight, the SW620 cells were transiently transfected with small interfering RNA (siRNA) against XLOC_010588 (si-XLOC_010588) or a nonspecific control siRNA (Guangzhou RiboBio Co., Ltd., Guangzhou, China) using Lipofectamine 2000 reagent (Invitrogen; Thermo Fisher Scientific, Inc.) according to the manufacturer's instructions. The sequences of the three designed XLOC_010588 siRNAs were as follows: si-XLOC_010588 \#1, GCAGGGATAGAGCTTGCTT; si-XLOC_010588 \#2, GCTGCTGACAGCAATTAAT; and si-XLOC_010588 \#3, GGTCCCTGCTTTGGTTTAA. At 48 h after transfection, the cells were harvested to detect the knockout efficiency via RT-qPCR.

For overexpression, the HCT116 cells were transiently transfected with plasmids (pcDNA3.1 or pcDNA3.1-XLOC_010588) (Hanbio Biotechnology Co., Ltd., Shanghai, China), with the subsequent steps being the same as those for the SW620 cell line.

After confirming that the cell models were successful, the cells were collected for the following experiments.

Wound healing assay. The SW620 and HCT116 cells were seeded into 6-well plates, and subjected to cell transfection. After the cells had been cultured to $\sim 90 \%$ confluence, the cell layer was scratched with a sterile $10-\mu 1$ pipette tip and washed three times with PBS to remove the detached cells. Subsequently, the scratch width change was observed at 0,6 , 24 and $48 \mathrm{~h}$ by light microscopy. Cell migration was measured using ImageJ 6.0 with the following formula: Migration area ratio $=$ the proportion of closed wound area/the whole field of view area.

Migration and invasion assay. Cell migration and invasion assays were performed using 24-well Transwell chambers (Corning Inc., Corning, NY, USA). For the migration assay, a total of $8 \times 10^{4}$ cells in serum-free media were seeded in the upper chambers after transfection for $24 \mathrm{~h}$, while medium containing $20 \%$ FBS was added to the lower chambers. The invasion assay was set up in the same way, except that the upper chambers were coated with Matrigel (BD Biosciences, Franklin Lakes, NJ, USA). After $48 \mathrm{~h}$ of incubation, the cells on the filter surface were fixed with $4 \%$ paraformaldehyde and stained with crystal violet. Under a light microscope, five high-power fields of view were randomly selected in which to count the cells.

Immunofluorescence (IF). Cells were seeded on $24 \times 24-\mathrm{mm}$ glass coverslips in 6-well plates. After transfection for $24 \mathrm{~h}$, the cells were washed three times with PBS and fixed with 4\% paraformaldehyde at room temperature for $30 \mathrm{~min}$. After a PBS wash, the cells were permeabilized with $0.1 \%$ Triton X-100. After further PBS washes, the cells were blocked with 5\% bovine serum albumin (BSA) for $30 \mathrm{~min}$ at room temperature, then incubated with primary antibodies (1:200; E-cadherin cat. no. 3195S; vimentin cat. no. 5741S, Slug cat. no. 9585P; all from Cell Signaling Technology, Inc., Beverly, MA, USA),
(1:200; E-cadherin cat. no. 610181; Slug cat. no. 564614; both from BD Biosciences), followed by fluorescent secondary antibodies for $30 \mathrm{~min}$ at room temperature (1:100; FITC-goat anti-mouse IgG cat. no. E031210-01; TRITC-goat anti-rabbit IgG cat. no. E031320-01; ZSGB-BIO, Beijing, China). The cells were subsequently washed with PBS, after which DAPI was used to stain the cell nuclei. The cells were observed using an inverted fluorescence microscope (Nikon Corp., Tokyo, Japan).

Western blotting. Total protein was extracted from the transfected cells using radioimmunoprecipitation assay (RIPA) buffer supplemented with the protease inhibitor phenylmethanesulfonyl fluoride (PMSF), and the concentration of total protein was measured using a BCA Protein assay kit (Beyotime Institute of Biotechnology, Haimen, China). Subsequently, the extracted protein samples were separated by $10 \%$ SDS-PAGE and transferred onto polyvinylidene difluoride (PVDF) membranes. Following blocking of the PVDF membranes with 5\% BSA at room temperature for $1 \mathrm{~h}$, the membranes were incubated with various antibodies (1:1,000; E-cadherin cat. no. 3195S; vimentin cat. no. 5741S; Slug cat. no. 9585P; all from Cell Signaling Technology, Inc.), (1:1,000; E-cadherin cat. no. 610181; Slug cat. no. 564614; both from $\mathrm{BD}$ Biosciences) at $4^{\circ} \mathrm{C}$ overnight, washed three times for 5 min each with $1 \mathrm{X}$ Tris-buffered saline with Tween-20 (TBST), and then incubated with secondary antibodies (1:2,500; ZB-2301 cat. no. 109525 ; ZB-2305 cat. no. 122627; ZSGB-BIO) at room temperature for $2 \mathrm{~h}$. Finally, the proteins were visualized by electrochemiluminescence (22).

Statistical analysis. All data are presented as the mean \pm standard deviation from three independent experiments. Student's t-tests or ANOVA analysis were used to estimate the statistical significance of differences between two groups or multiple groups regarding clinical data and the results of cell experiments. Survival curves were analyzed by the Kaplan-Meier method with the log-rank test. $\mathrm{P}<0.05$ was considered to indicate a statistically significant difference. Statistical analyses were performed using SPSS software (version 18.0; SPSS, Inc., Chicago, IL, USA) and presented using GraphPad Prism software (version 6; GraphPad Software, Inc., La Jolla, CA, USA).

\section{Results}

XLOC_010588 is upregulated in human CRC tissues and associated with aggressive phenotypes. To explore the association between the expression of XLOC_010588 in CRC and the clinicopathological data of the patients, we performed an in situ hybridization analysis on 111 cancer tissue samples and 70 normal adjacent tissues from CRC patients (Table I). The results demonstrated that XLOC_010588 was specifically stained in both malignant epithelial cells and benign epithelial cells (Fig. 1). We used the ROC curve to obtain cutoff value (cutoff value $=155)($ Fig. 2), and the statistical results indicated that XLOC_010588 was expressed at a high level in 58.02\% of the cancer tissues but only $24.29 \%$ of normal adjacent tissues $(\mathrm{P}<0.001$; Fig. 3). We subsequently analyzed the expression level of XLOC_010588 with regard to clinicopathological data 
Table I. Clinical and pathological characteristics of patients with CRC in the present study.

\begin{tabular}{|c|c|c|}
\hline Parameters & No. of patients & $\%$ \\
\hline Total number & 111 & 100 \\
\hline \multicolumn{3}{|l|}{ Age (years) } \\
\hline$\leq 60$ & 45 & 40.5 \\
\hline$>60$ & 65 & 58.6 \\
\hline Unknown & 1 & 0.9 \\
\hline \multicolumn{3}{|l|}{ Sex } \\
\hline Male & 65 & 58.6 \\
\hline Female & 46 & 41.4 \\
\hline \multicolumn{3}{|l|}{ Size $(\mathrm{cm})$} \\
\hline$\leq 5$ & 54 & 48.7 \\
\hline$>5$ & 55 & 49.5 \\
\hline Unknown & 2 & 1.8 \\
\hline \multicolumn{3}{|c|}{ Histology grade } \\
\hline I-II & 81 & 73 \\
\hline III & 30 & 27 \\
\hline \multicolumn{3}{|l|}{ T-stages } \\
\hline $1-2$ & 45 & 40.5 \\
\hline $3-4$ & 35 & 31.5 \\
\hline Unknown & 31 & 28 \\
\hline \multicolumn{3}{|l|}{ N-stages } \\
\hline Yes & 33 & 29.7 \\
\hline No & 71 & 64 \\
\hline Unknown & 7 & 6.3 \\
\hline \multicolumn{3}{|l|}{ M-stages } \\
\hline Yes & 4 & 3.6 \\
\hline No & 107 & 96.4 \\
\hline
\end{tabular}

CRC, colorectal cancer.

in patients with CRC, and observed that the expression level of XLOC_010588 was significantly associated with patient sex $(\mathrm{P}=0.03)$, T-stage $(\mathrm{P}=0.013)$ and lymph node metastasis $(\mathrm{P}=0.002)$, whereas it was not associated with patient age, tumor size, tumor differentiation degree and distant metastasis (all $\mathrm{P}>0.05$; Table II).

Upregulation of XLOC_O10588 is associated with poor prognosis in patients with $C R C$. To ascertain the effect of XLOC_010588 on the prognosis of CRC patients, the expression of XLOC_010588 was analyzed with regard to the survival rate of CRC patients using the Kaplan-Meier method and the log-rank test. The results indicated that the expression level of XLOC_010588 was closely associated with the survival rate of CRC patients, with higher expression being associated with a lower survival rate (log-rank $=16.353, \mathrm{P}<0.001$, Fig. 4A). We further performed a stratified analysis of XLOC_010588 expression with regard to tumor size, histological grade, T- and $\mathrm{N}$-stages. The results revealed that, regardless of tumor size, the expression level of XLOC_010588 and the survival period of CRC patients were related (log-rank $=4.490, P=0.034$, Fig. 4B;
Table II. Correlation between the clinicopathological features and the expression of XLOC-010588.

\begin{tabular}{|c|c|c|c|c|}
\hline \multirow[b]{2}{*}{ Characteristics } & \multirow[b]{2}{*}{ No. of patients } & \multicolumn{2}{|c|}{$\begin{array}{c}\text { XLOC } \\
\text { expression }\end{array}$} & \multirow[b]{2}{*}{ P-value } \\
\hline & & High & Low & \\
\hline Age (years) & $110 / 111$ & & & 0.846 \\
\hline$\leq 60$ & 45 & 23 & 22 & \\
\hline$>60$ & 65 & 32 & 33 & \\
\hline Sex & $111 / 111$ & & & 0.03 \\
\hline Male & 65 & 26 & 39 & \\
\hline Female & 46 & 28 & 18 & \\
\hline Size $(\mathrm{cm})$ & $109 / 111$ & & & 0.502 \\
\hline$\leq 5$ & 54 & 25 & 29 & \\
\hline$>5$ & 55 & 29 & 26 & \\
\hline Histology grade & $111 / 111$ & & & 0.862 \\
\hline I-II & 81 & 39 & 42 & \\
\hline III & 30 & 15 & 15 & \\
\hline T-stages & $80 / 113$ & & & 0.013 \\
\hline $1-2$ & 45 & 21 & 24 & \\
\hline $3-4$ & 35 & 26 & 9 & \\
\hline N-stages & $111 / 111$ & & & 0.002 \\
\hline Yes & 33 & 24 & 9 & \\
\hline No & 71 & 28 & 43 & \\
\hline Unknown & 7 & & & \\
\hline M-stages & $111 / 111$ & & & 0.065 \\
\hline Yes & 4 & 4 & 0 & \\
\hline No & 107 & 57 & 50 & \\
\hline
\end{tabular}

log-rank $=10.079, \mathrm{P}=0.001$, Fig. $4 \mathrm{C})$. Additionally, in CRC patients with histological grade I/II tumors (log-rank $=14.474$, $\mathrm{P}<0.001$; Fig. 4D), T-stage $1 / 2$ tumors (log-rank $=9.455$, $\mathrm{P}=0.002$; Fig. 4F) and the absence of lymph node metastasis (log-rank $=13.089, \mathrm{P}<0.001$; Fig. 4I), XLOC_010588 expression was significantly associated with the survival rate, whereas no such association was observed in patients with histological grade III tumors, T-stage 3/4 tumors and lymph node metastasis $(\mathrm{P}>0.05$; Fig. $4 \mathrm{E}, \mathrm{G}$ and $\mathrm{H})$. To confirm whether the expression of XLOC_010588 is an independent risk factor that affects the prognosis of CRC, we performed univariate and multivariate analyses based on the data referring to the Kaplan-Meier analysis of overall survival with regard to patient clinicopathological features, and the results revealed that high expression of XLOC_010588 was an independent risk factor for poor prognosis in $\mathrm{CRC}(\mathrm{P}=0.005$; Table III).

XLOC_010588 expression is generally increased in human CRC cell lines. The literature reports that low expression of XLOC_010588 indicates a poor prognosis and promotes cell proliferation through upregulation of c-Myc in cervical cancer. To define the role of XLOC_010588 in CRC, we performed an RT-qPCR analysis to examine the expression of XLOC_010588 in 5 human CRC cell lines, namely Caco-2, 
A

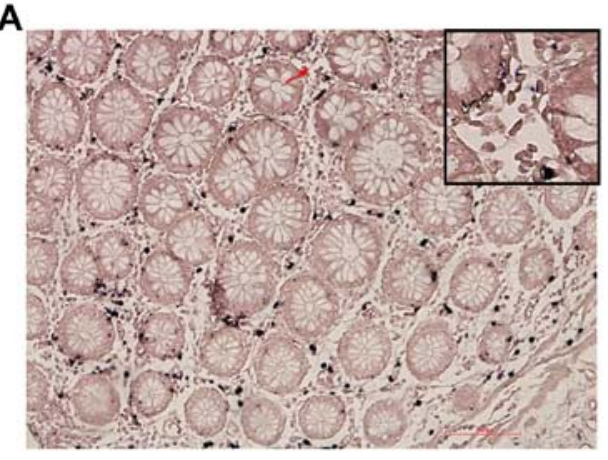

C

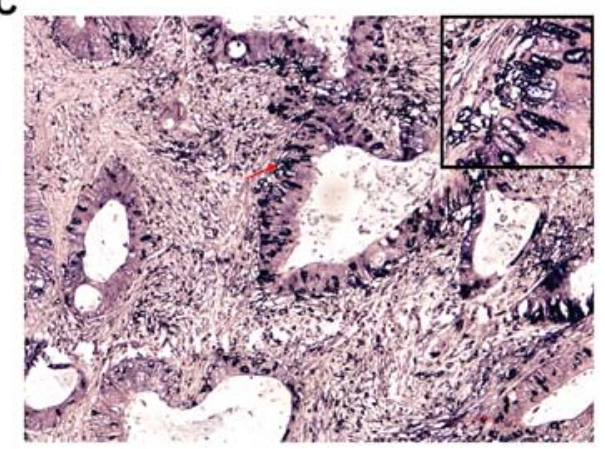

B

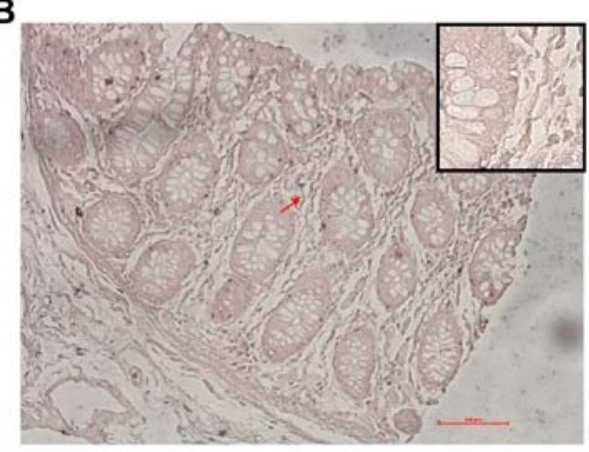

D

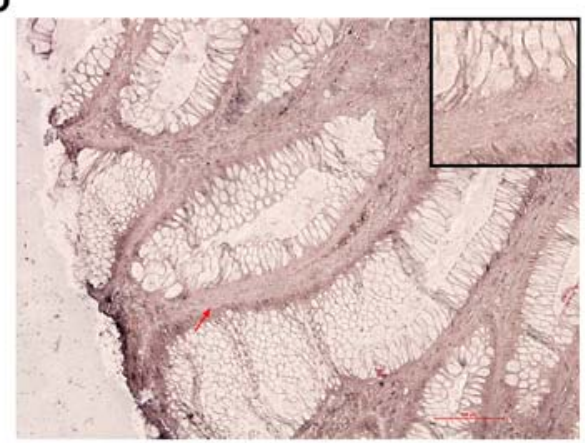

Figure 1. Levels of XLOC_010588 expression in CRC tissues determined by in situ hybridization. (A) Positive expression of XLOC_010588 in adjacent normal tissues. (B) Negative expression of XLOC_010588 in adjacent normal tissues. (C) Positive expression of XLOC_010588 in CRC tissues. (D) Negative expression of XLOC_010588 in CRC tissues. The tissues were evaluated by microscopy (x200); red arrows indicate the enlarged area (top right corner, $\mathrm{x} 400$ ). $\mathrm{CRC}$, colorectal cancer.

A

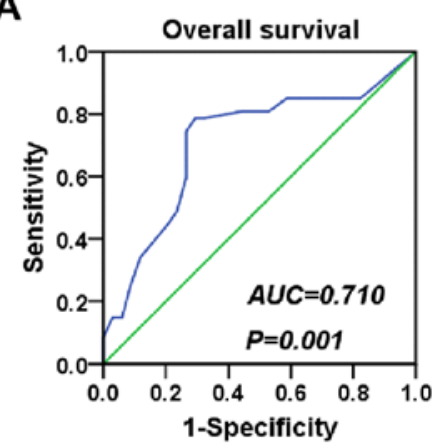

D

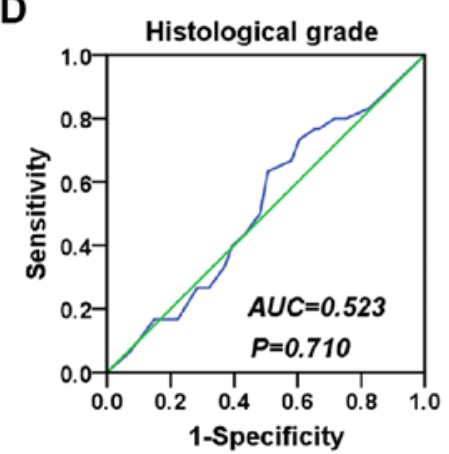

B

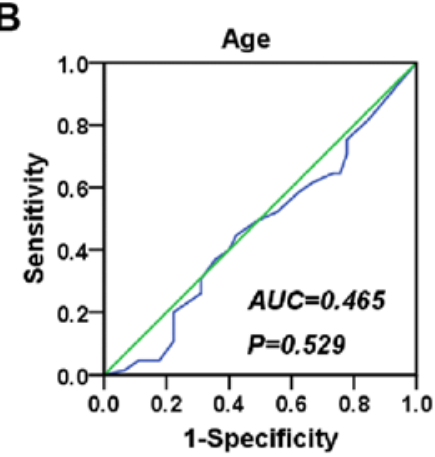

E

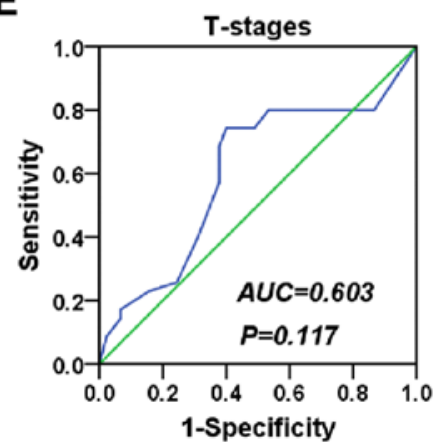

C

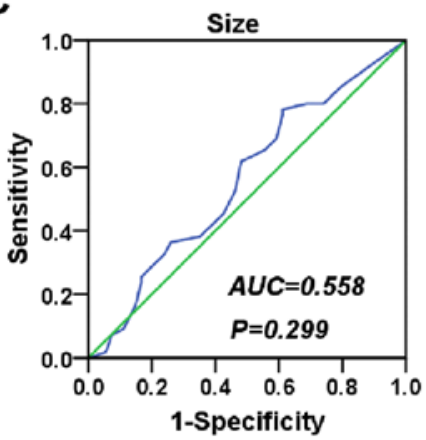

$\mathbf{F}$

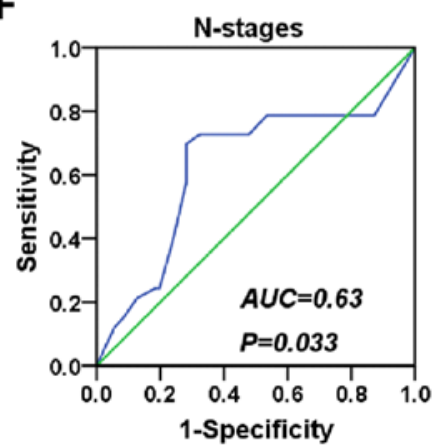

Figure 2. ROC curve analysis of clinicopathological features. (A) The ROC curve depicting patient survival exhibited the largest area under the curve (P=0.001), and thus we used this ROC curve to obtain a cutoff value. (B-F) ROC curves of other clinicopathological features. ROC, receiver operating characteristic.

HT-29, SW480, SW620 and HCT116, and in the normal human intestinal epithelial cell line HIEC-6. The results demonstrated that XLOC_010588 expression in the majority of the CRC cell lines was markedly higher than that in the 
Table III. Summary of overall survival analyses by univariate and multivariate COX regression analysis.

\begin{tabular}{|c|c|c|c|c|c|c|}
\hline \multirow[b]{2}{*}{ Factor } & \multicolumn{3}{|c|}{ Univariate analysis } & \multicolumn{3}{|c|}{ Multivariate analysis } \\
\hline & $\mathrm{RR}$ & $95 \%$ CI & $\mathrm{P}$-value & RR & $95 \% \mathrm{CI}$ & $\mathrm{P}$-value \\
\hline Age (years) & 1.504 & $0.826-2.736$ & 0.182 & & & \\
\hline Sex & 0.825 & $0.480-1.416$ & 0.485 & & & \\
\hline Tumor size & 1.496 & $0.868-2.577$ & 0.147 & & & \\
\hline Histological grade & 2.948 & $1.618-5.369$ & $<0.001$ & 2.478 & $1.238-4.960$ & 0.010 \\
\hline T-stages & 3.020 & $1.735-5.257$ & $<0.001$ & 4.484 & $0.962-20.89$ & 0.056 \\
\hline $\mathrm{N}$-stages & 2.873 & $1.626-5.076$ & $<0.001$ & 0.475 & $0.107-2.117$ & 0.329 \\
\hline M-stages & 2.380 & $0.850-6.667$ & 0.099 & & & \\
\hline XLOC expression & 3.848 & $1.901-7.788$ & $<0.001$ & 3.233 & $1.431-7.302$ & 0.005 \\
\hline
\end{tabular}

$\mathrm{CI}$, confidence interval; RR, relative risk.

A

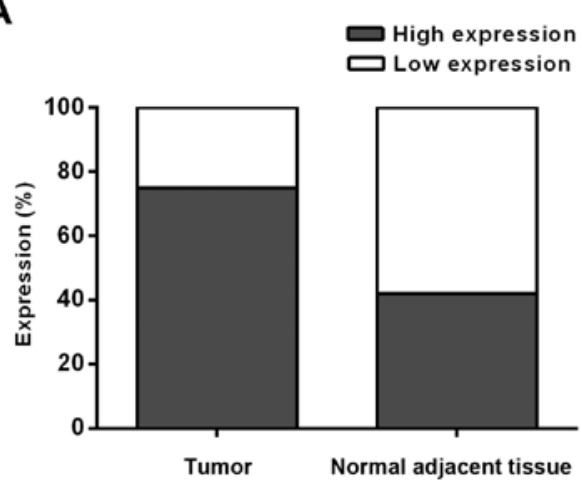

B

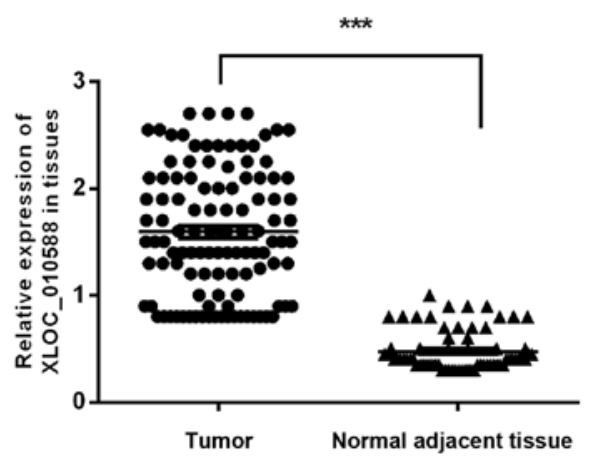

Figure 3. Expression of XLOC_010588 in CRC tissues and adjacent normal tissues. (A and B) Expression levels of XLOC_010588 in CRC and adjacent normal tissues. High expression of XLOC_010588 was more predominant in the CRC tissues $\left({ }^{* * * *} \mathrm{P}<0.001\right)$. CRC, colorectal cancer.

HIEC cells (Fig. 5A). Among the CRC cells, XLOC_010588 expression was significantly increased in the SW620 cells $(\mathrm{P}<0.01)$, and thus these cells were used as a model for RNAi knockdown of XLOC_010588. Conversely, HCT116 cells exhibited a similar expression level of XLOC_010588 to that of the controls, and thus were used as a model for pcDNA3.1-XLOC_010588 transfection. The SW620 and HCT116 cells were used in subsequent experiments to assess cell migration and invasion in CRC in vitro.

XLOC_010588 promotes cell invasion and migration in $C R C$ cell lines in vitro. Due to the markedly high expression of XLOC_010588 in CRC cell lines, particularly in SW620 cells, we hypothesized that XLOC_010588 may be associated with the invasion and migration of $\mathrm{CRC}$, and potentially serve a crucial role in these processes. To verify this hypothesis, we silenced XLOC_010588 in SW620 cells using siRNA, while overexpressing XLOC_010588 in HCT116 cells, after which RT-qPCR was performed at $48 \mathrm{~h}$ post-transfection to confirm the silencing and overexpression efficiencies. We determined that XLOC_010588 expression was markedly decreased following transfection with si-XLOC_010588 $(\mathrm{P}=0.009$; Fig. 5B), and increased following transfection with pcDNA3.1-XLOC_010588 (P<0.001; Fig. 5C).
The subsequent wound-healing assay revealed that XLOC_010588 silencing inhibited cell migration when compared with si-control transfection $(\mathrm{P}<0.05$; Fig. $6 \mathrm{~A}$ and $\mathrm{C})$, while the overexpression of XLOC_010588 promoted cell migration $(\mathrm{P}<0.05$; Fig. $6 \mathrm{~B}$ and $\mathrm{D})$. Furthermore, through the Transwell assays, we observed that si-XLOC_010588 interference significantly reduced cell migration and invasion abilities compared with the si-control $(\mathrm{P}<0.001$; Fig. 7A and $\mathrm{C})$, while cell invasion and migration abilities following XLOC_00588 overexpression were significantly enhanced compared with the control group $(\mathrm{P}<0.001$; Fig. $7 \mathrm{~B}$ and $\mathrm{D})$.

XLOC_O10588 in CRC cells promotes the EMT pathway in CRC cells. The migration and invasion assays demonstrated that si-XLOC_010588 treatment significantly impaired cell migration and invasion capacities compared with si-control, while the overexpression cell model exhibited the opposite results. On account of EMT being an important factor in cell migration and invasion, and to further investigate the underlying mechanism of XLOC_010588 in CRC cell migration and invasion, it was next analyzed whether XLOC_010588 regulated EMT signaling. The expression levels of E-cadherin, vimentin and Slug were analyzed by western blotting (Fig. 8), RT-qPCR (Fig. 9A and B) and 
A

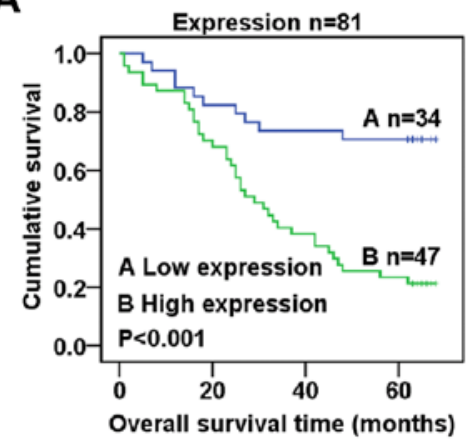

Number at risk
B

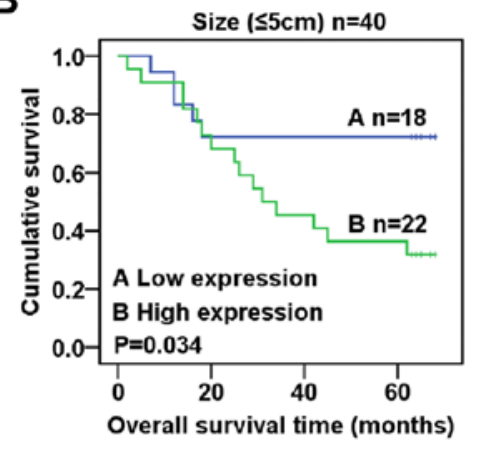

Number at rısk

$\begin{array}{rrrrrr}\text { A } & 18 & 14 & 14 & 14 & 3 \\ \text { B } & 22 & 16 & 10 & 8 & 1\end{array}$

C

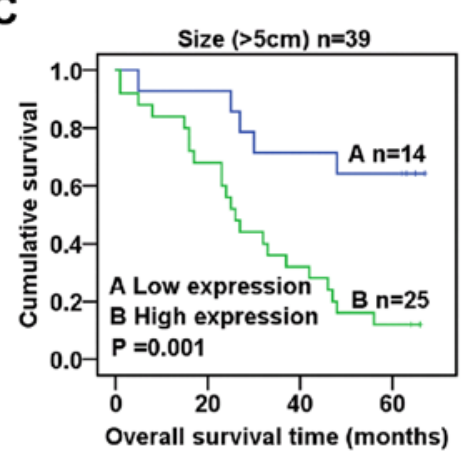

Number at risk

$\begin{array}{llllll}A & 14 & 14 & 11 & 9 & 0\end{array}$

D

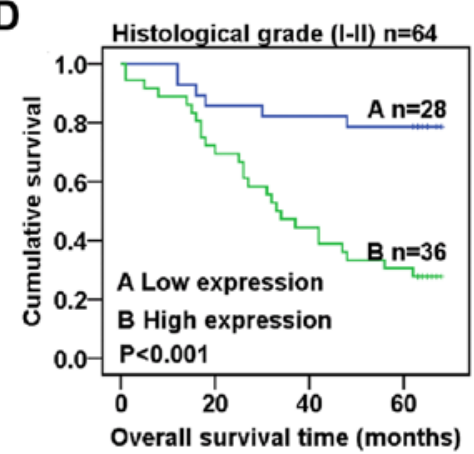

Number at risk
E

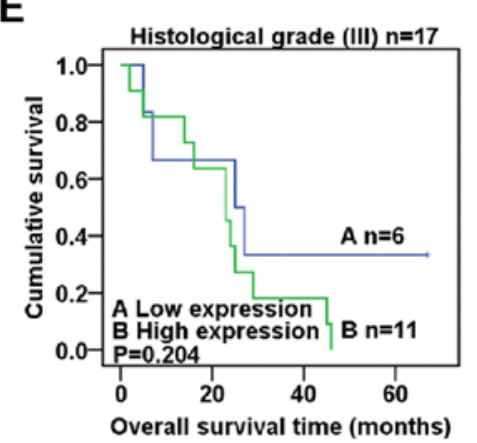

Number at risk
F

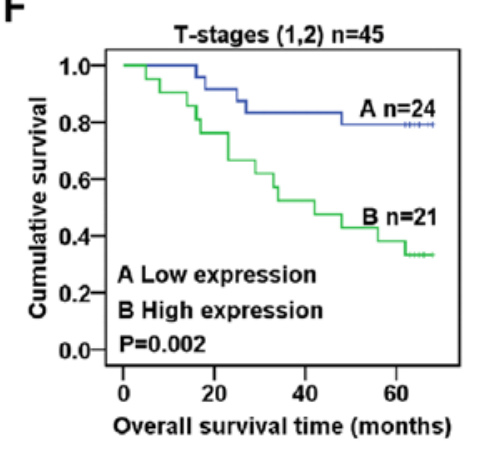

Number at risk

$\begin{array}{cccccc}\text { A } & 24 & 23 & 21 & 19 & 3 \\ \text { B } & 21 & 16 & 11 & 8 & 1\end{array}$

G

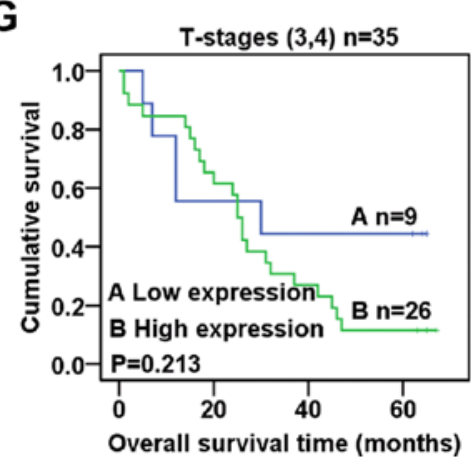

Number at risk
H

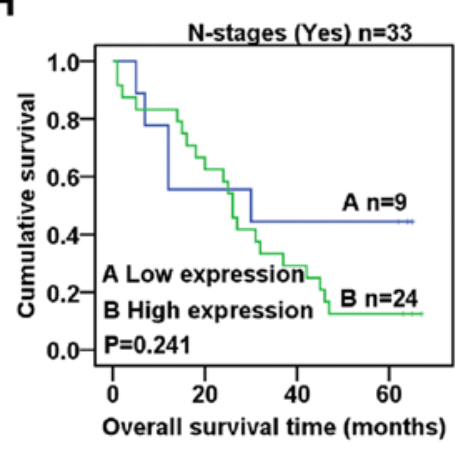

Number at risk

$\begin{array}{cccccc}\text { A } & 9 & 7 & 5 & 4 & 0 \\ \text { B } & 24 & 16 & 7 & 4 & 0\end{array}$

I

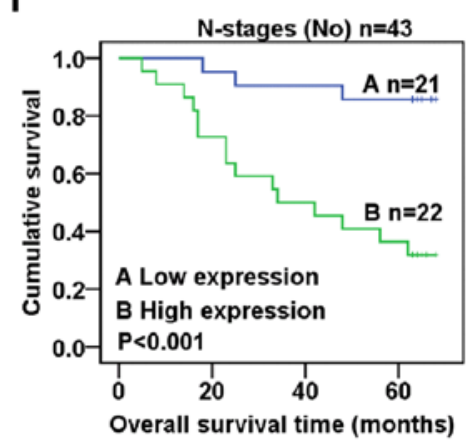

Number at risk
$\begin{array}{llllll}\text { A } & 21 & 21 & 20 & 19 & 3\end{array}$
$\begin{array}{llllll}\text { B } & 22 & 16 & 11 & 8 & 1\end{array}$

Figure 4. Kaplan-Meier analysis of overall survival with regard to patient clinicopathological features. (A) Kaplan-Meier analysis of the overall survival rate of patients expressing XLOC_010588 ( $\mathrm{P}<0.001)$. (B and C) Association between the expression level of XLOC_010588 and patient prognosis when tumor size was $(\mathrm{B}) \leq 5 \mathrm{~cm}(\mathrm{P}=0.001)$ or $(\mathrm{C})>5 \mathrm{~cm}(\mathrm{P}=0.034)$. ( $\mathrm{D}$ and $\mathrm{E})$ Association between the expression level of XLOC_010588 and patient prognosis when tumor histological grade was (D) I-II $(\mathrm{P}<0.001)$ or $(\mathrm{E})$ III $(\mathrm{P}=0.204)$. ( $\mathrm{F}$ and $\mathrm{G})$ Association between the expression level of XLOC_010588 and patient prognosis when tumor T-stage was $(\mathrm{F})$ 1-2 ( $\mathrm{P}=0.002)$ or $(\mathrm{G}) 3-4(\mathrm{P}=0.213)$. (H and I) Association between the expression level of XLOC_010588 and patient prognosis when lymph node metastasis was $(\mathrm{H})$ present $(\mathrm{P}=0.241)$ or $(\mathrm{I})$ absent $(\mathrm{P}<0.001)$.

immunofluorescence (Fig. 9C and D). We determined that the knockdown of XLOC_010588 markedly promoted E-cadherin expression at the mRNA $(\mathrm{P}<0.01)$ and protein
$(\mathrm{P}<0.001)$ levels, while reducing the mRNA and protein levels of Slug (both $\mathrm{P}<0.01)$ and vimentin $(\mathrm{P}<0.01$ and $\mathrm{P}<0.05$, respectively). 


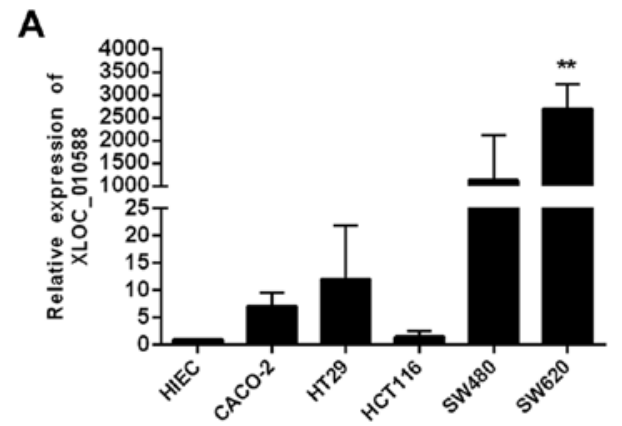

B

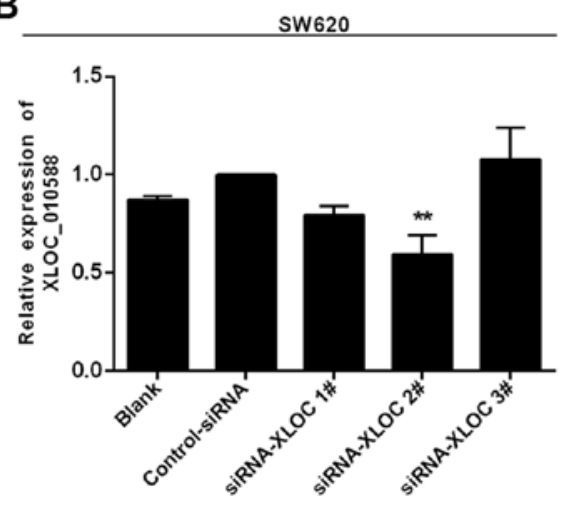

C

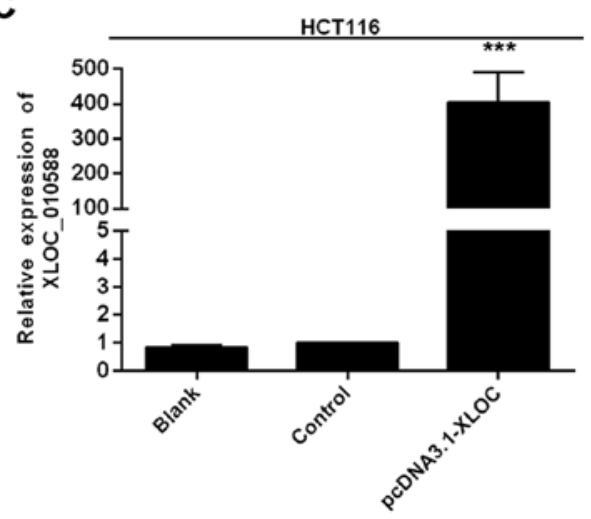

Figure 5. XLOC_010588 expression levels and knockdown/overexpression efficiency of XLOC010588 in CRC cells. (A) Results of RT-qPCR displaying the expression level of XLOC_010588 mRNA in CRC cell lines. XLOC_010588 expression was significantly increased in SW620 cells ( $\left({ }^{* *} \mathrm{P}<0.01 \mathrm{vs}\right.$. HIEC control), while the expression of XLOC_010588 in HCT116 cells was the lowest among all the CRC cell lines (P>0.05 vs. HIEC control). (B) Results of RT-qPCR revealing that the expression of XLOC_010588 mRNA in SW620/si cells was markedly decreased compared with that in the control cells, particularly in cells transfected with si-XLOC_010588 2\# ("P<0.01). (C) Results of RT-qPCR revealing that the expression of XLOC_010588 mRNA in HCT116/plasmid cells was increased compared with that in control cells $\left({ }^{* * *} \mathrm{P}<0.001\right)$. CRC, colorectal cancer.

A

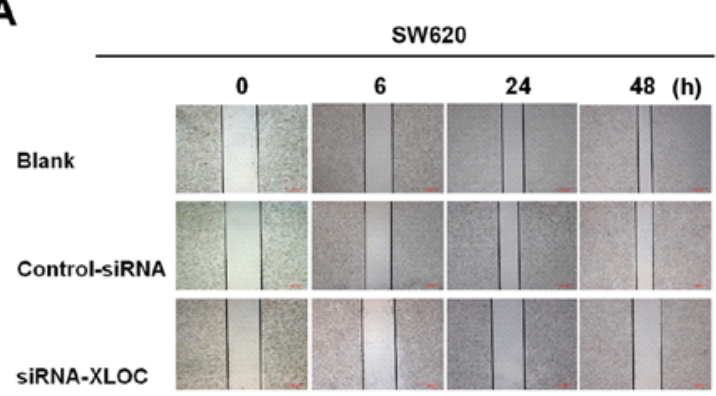

C

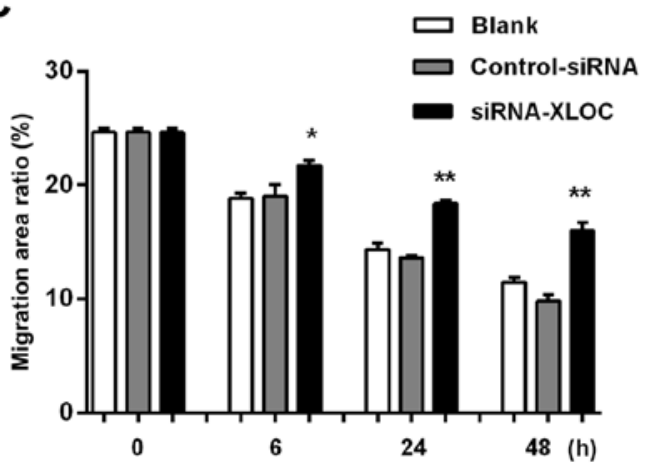

B

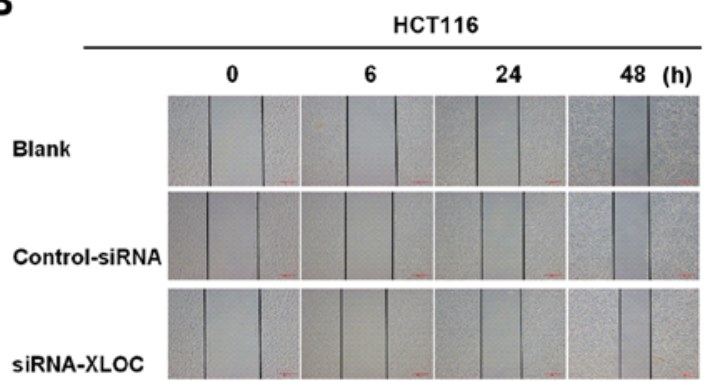

D

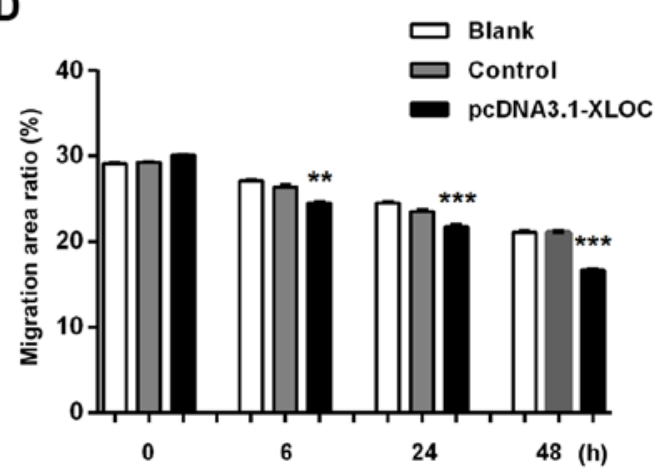

Figure 6. (A-D) XLOC_010588 promotes cell migration. (A and C) XLOC_010588 silencing inhibited cell migration in a wound-healing assay after 6 ("P $<0.05$ ), $24\left({ }^{* *} \mathrm{P}<0.01\right)$ and $48 \mathrm{~h}\left({ }^{* *} \mathrm{P}<0.01\right)$. (B and D) XLOC_010588 overexpression promoted cell migration in a wound healing assay after $\left.6{ }^{* * *} \mathrm{P}<0.01\right), 24\left({ }^{* * *} \mathrm{P}<0.001\right)$ and $48 \mathrm{~h}\left({ }^{* * *} \mathrm{P}<0.001\right)$. The cells were observed by microscopy $(\mathrm{x} 100)$. 
A

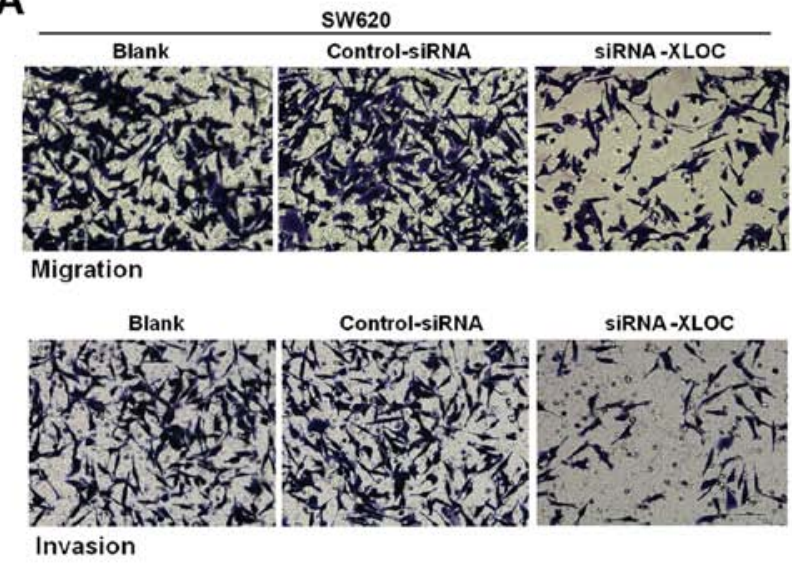

B
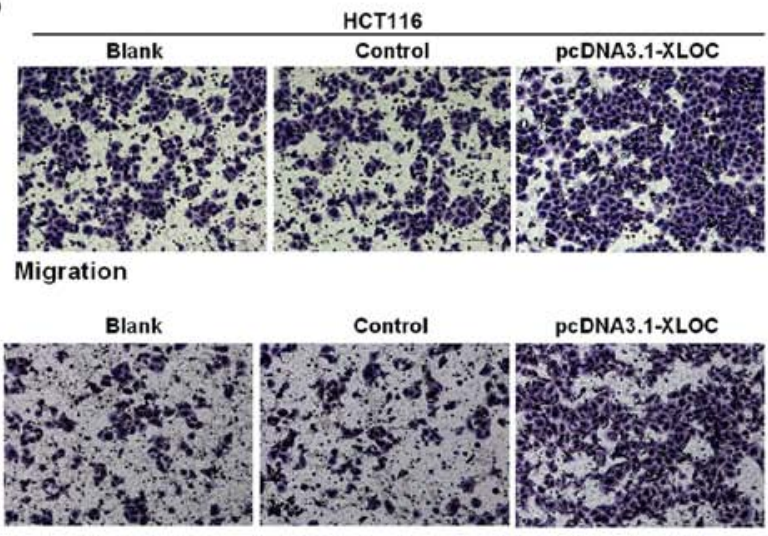

Invasion

D
C

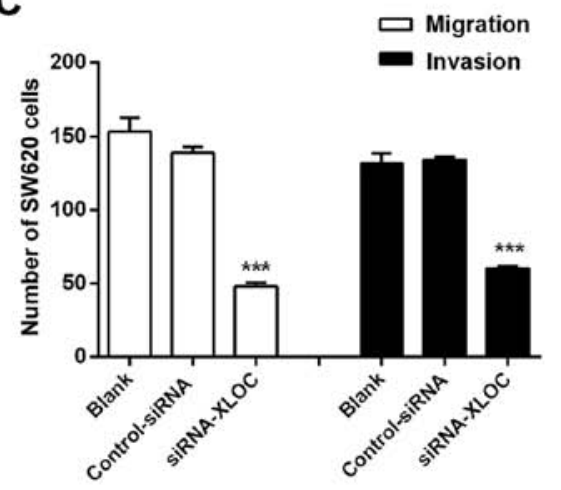

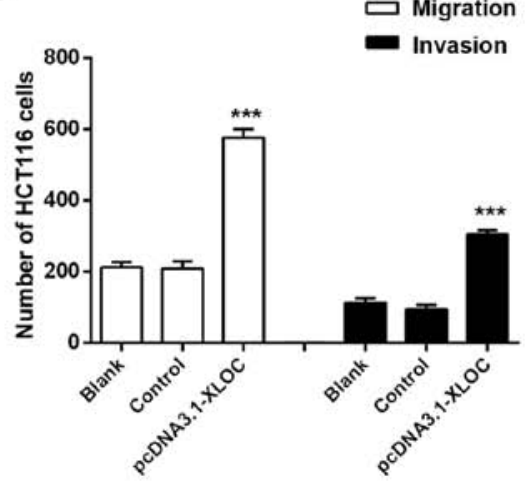

Figure 7. XLOC_010588 promotes cell migration and invasion in Transwell assays. (A and C) XLOC_010588 silencing inhibited cell migration $\left.{ }^{* * * *} \mathrm{P}<0.001\right)$ and invasion $\left({ }^{* * *} \mathrm{P}<0.001\right)$ in SW620 cells. (B and D) XLOC_010588 overexpression promoted cell migration $\left({ }^{* * * *} \mathrm{P}<0.001\right)$ and invasion $\left.{ }^{(* * *} \mathrm{P}<0.001\right)$ in HCT116 cells. The cells were observed by microscopy (x200).

\section{Discussion}

In recent years, diagnostic and therapeutic techniques have undergone rapid development, and the mortality rate of CRC patients has markedly decreased as a consequence, while the quality of life of patients has improved substantially. However, metastasis and recurrence remain key factors that lead to poor prognosis of $\mathrm{CRC}$ patients, and further investigation into the pathogenesis of CRC, to ultimately identify more effective treatments for this fatal disease, is therefore required $(1,24)$. Recent studies have demonstrated that ncRNAs play multiple roles in biological processes and human diseases; thus, they have become a focus of research for biologists and clinicians $(1,25)$. Compared with protein-coding genes, non-coding genes appear to be expressed at a lower level. However, evidence has ascertained that these non-coding genes are closely associated with certain human tumor types, including CRC (18).

Certain ncRNAs have been recognized as contributing factors in CRC. However, there is still a lack of relevant evidence to demonstrate their functions and underlying mechanisms in CRC (22). Previous studies have revealed a potential key role of IncRNAs in CRC. Notably, an experiment by Liao et al revealed that XLOC_010588 expression was downregulated in cervical cancer, which was the first time this phenomenon was reported (16). However, the results of the present study revealed that XLOC_010588 was expressed at a higher level in cancer tissues compared with adjacent normal tissues. Furthermore, it was also overexpressed in a panel of CRC cell lines, and thus we suspect that XLOC_010588 has a cancer-specific expression pattern, indicating that XLOC_010588 may act as an oncogene or tumor suppressor in different cancer types $(7,17)$. A survey of the available literature indicates that XLOC_010588 promotes cell proliferation through upregulation of c-Myc in cervical cancer (16). In the present experiment, we attempted to ascertain, besides its role in tumor proliferation, whether XLOC_010588 participates in the processes of invasion and migration in CRC (6). EMT is the process by which tumor cells differentiate into mesenchymal cells, which have an increased capacity to obtain movement ability; during this process, cells gradually reorganize or downregulate their cytoskeleton and basal epithelial-specific epithelial genes, including (E)-cadherin, while simultaneously upregulating expression of vimentin and Slug, with Slug further suppressing the expression of E-cadherin. This EMT process is typically observed during tumor invasion and migration (26). Recently, a number of studies have established lncRNAs to play a dominant role in the regulation of EMT (8), and a range of EMT-related lncRNAs have been identified, including lncRNA-GHET1, lncRNA-SPRY4 and lncRNA-TUG1, among others. Therefore, we speculated that XLOC_010588 is also a potential EMT-related lncRNA (7). In the present study, we demonstrated that the abilities of CRC cells to invade and migrate were weakened when 
A

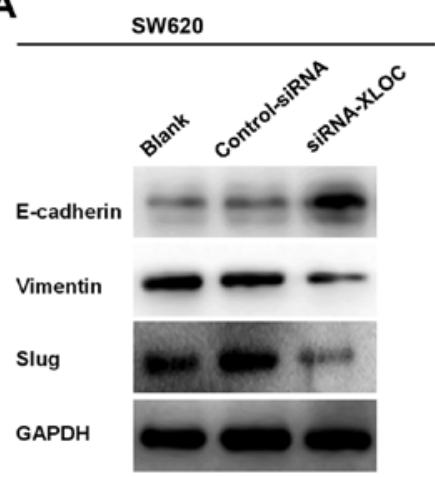

C

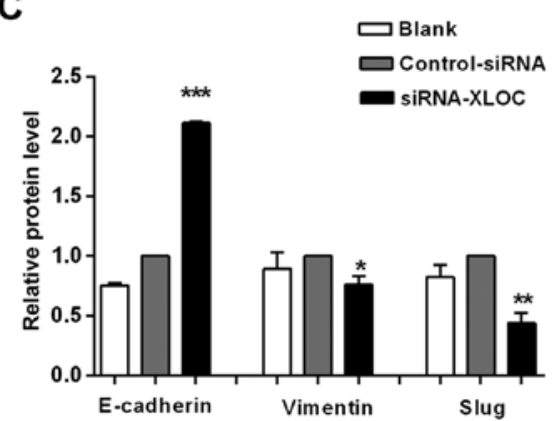

B

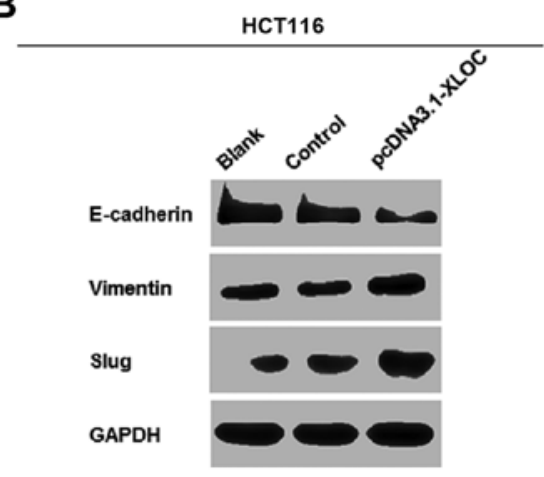

D

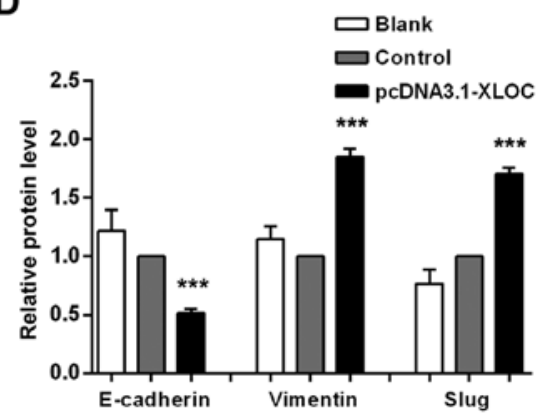

Figure 8. XLOC_010588 affects EMT in SW620 and HCT116 cells. (A and C) Western blotting results srevealed that XLOC_010588 downregulation increased E-cadherin expression $\left({ }^{* * *} \mathrm{P}<0.001\right)$ while reducing Slug $\left({ }^{*} \mathrm{P}<0.05\right)$ and vimentin $\left.{ }^{* *} \mathrm{P}<0.01\right)$ levels. (B and $\left.\mathrm{D}\right)$ Western blotting results revealed that XLOC_010588 overexpression reduced E-cadherin expression $\left({ }^{* * * *} \mathrm{P}<0.001\right)$ while increasing Slug $\left({ }^{* * *} \mathrm{P}<0.001\right)$ and vimentin $\left({ }^{* * *} \mathrm{P}<0.001\right)$ levels. EMT, epithelial-mesenchymal transition.

A

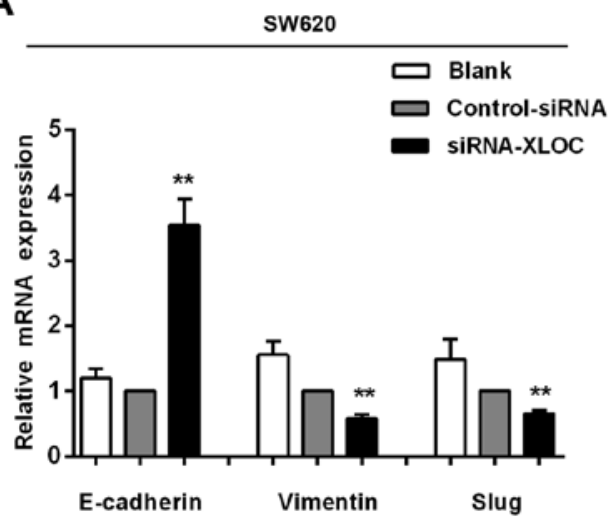

C

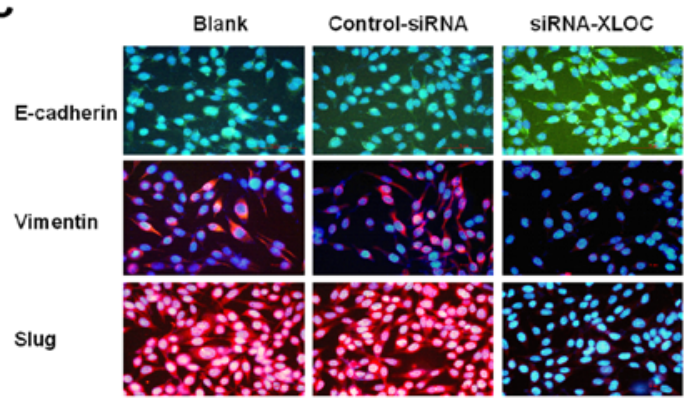

B

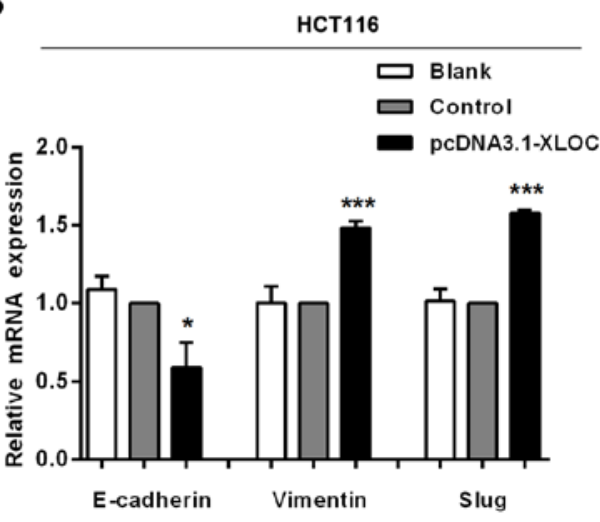

D

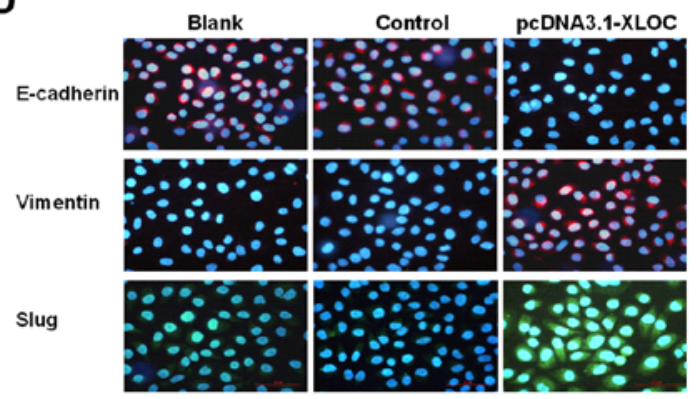

Figure 9. XLOC_010588 affects EMT in SW620 and HCT116 cells. (A) RT-qPCR results demonstrated that XLOC_010588 downregulation increased E-cadherin expression $\left({ }^{* *} \mathrm{P}<0.01\right)$ while reducing Slug $\left({ }^{* *} \mathrm{P}<0.01\right)$ and vimentin $\left({ }^{* *} \mathrm{P}<0.01\right)$ levels. (B) RT-qPCR results demonstrated that $\mathrm{XLOC} \_010588$ overexpression reduced E-cadherin expression $\left({ }^{*} \mathrm{P}<0.05\right)$ while increasing Slug $\left({ }^{* * * *} \mathrm{P}<0.001\right)$ and vimentin $\left({ }^{* * * *} \mathrm{P}<0.001\right)$ levels. $(\mathrm{C}$ and $\mathrm{D}) \mathrm{Results}$ of immunofluorescence revealed the same conclusions as the RT-qPCR and western blot analyses; the cells were observed by fluorescence microscopy (x200). EMT, epithelial-mesenchymal transition. 
XLOC_010588 was knocked down, while these abilities were enhanced when XLOC_010588 was overexpressed. We also ascertained the expression levels of EMT markers in SW620 cells and HCT116 cells, revealing that the overexpression of XLOC_010588 decreased the expression of E-cadherin and increased the expression of vimentin and Slug, while the knockdown of XLOC_010588 reversed these effects $(17,27)$. Overall these results indicated that XLOC_010588 affected the invasion and migration of CRC by regulating EMT-related genes.

In conclusion, our experiment revealed the relationship between XLOC_010588 expression and CRC for the first time. We established that XLOC_010588 was expressed at a higher level in cancer tissues compared with adjacent normal tissues, and that this high expression was closely associated with CRC T-stage and lymph node metastasis. However, due to there being a small sample size of patients with distant metastasis, we did not obtain significant data regarding XLOC_010588 expression and distant metastasis, and thus further research on this is warranted. Kaplan-Meier analysis also revealed that XLOC_010588 overexpression in tumor tissues was strongly connected with poorer prognosis of CRC patients. These results indicated that XLOC_010588 promotes the progression of CRC, and may serve as a negative prognostic factor for CRC patients. Furthermore, our study demonstrated that the expression of XLOC_010588 was markedly higher in CRC cells, and that XLOC_010588 promoted the invasion and migration of CRC cells. It was also revealed that XLOC_010588 may regulate the progression of CRC via the EMT pathway (28). In our experiments, we revealed a crucial role of XLOC_010588 in the invasion and migration of CRC. However, the specific mechanism underlying this effect of XLOC_010588, potentially involving regulation of the EMT pathway, requires further investigation in our future studies. In conclusion, the present findings indicated that XLOC_010588 is a functional oncogene, and revealed that XLOC_010588 may be a novel therapeutic target in patients with CRC $(29,30)$.

\section{Acknowledgements}

The authors would like to thank Dr LJ and SL (Department of Pharmacology, School of Pharmaceutical Sciences, China Medical University) for their help with the statistical analysis.

\section{Funding}

No funding was received.

\section{Availability of data and materials}

The datasets used and/or analyzed during the present study are available from the corresponding author on reasonable request.

\section{Authors' contributions}

YL, LZ and MS conceived and designed the study. YL and TG performed the experiments. YL wrote the study. YL, MS, LZ, YZ, LG, HZhang, HZhou and PM reviewed and edited the manuscript. All authors read and approved the manuscript.

\section{Ethics approval and consent to participate}

In the present study, all tissue microarrays were purchased from Shanghai Outdo Biotech Co., Ltd., and were approved by the local Ethics Committee (Zhejiang Taizhou Hospital Ethics Committee, Zhejiang, China). Due to the retrospective nature of the study, the Ethics Committee waived the requirement for written informed consent from the patients.

\section{Consent for publication}

Not applicable.

\section{Competing interests}

The authors declare that they have no competing interests.

\section{References}

1. Wang F, Ni H, Sun F, Li M and Chen L: Overexpression of IncRNA AFAP1-AS1 correlates with poor prognosis and promotes tumorigenesis in colorectal cancer. Biomed Pharmacother 81: 152-159, 2016.

2. Chen X, Liu B, Yang R, Guo Y, Li F, Wang L and Hu H: Integrated analysis of long non-coding RNAs in human colorectal cancer. Oncotarget 7: 23897-23908, 2016.

3. Sun L, Xue H, Jiang C, Zhou H, Gu L, Liu Y, Xu C and Xu Q: lncRNA DQ786243 contributes to proliferation and metastasis of colorectal cancer both in vitro and in vivo. Biosci Rep 36: e00328, 2016.

4. Chen X, Zhu H, Wu X, Xie X, Huang G, Xu X, Li S and Xing C: Downregulated pseudogene CTNNAP1 promote tumor growth in human cancer by downregulating its cognate gene CTNNA1 expression. Oncotarget 7: 55518-55528, 2016.

5. Han D, Gao X, Wang M, Qiao Y, Xu Y, Yang J, Dong N, He J, Sun Q, Lv G, et al: Long noncoding RNA H19 indicates a poor prognosis of colorectal cancer and promotes tumor growth by recruiting and binding to eIF4A3. Oncotarget 7: 22159-22173, 2016.

6. Ye LC, Chen T, Zhu DX, Lv SX, Qiu JJ, Xu J, Yuan FL and Wei Y: Downregulated long non-coding RNA CLMAT3 promotes the proliferation of colorectal cancer cells by targeting regulators of the cell cycle pathway. Oncotarget 7: 58931-58938, 2016.

7. Kong J, Sun W, Li C, Wan L, Wang S, Wu Y, Xu E, Zhang H and Lai M: Long non-coding RNA LINC01133 inhibits epithelial-mesenchymal transition and metastasis in colorectal cancer by interacting with SRSF6. Cancer Lett 380: 476-484, 2016.

8. Zhou J, Li X, Wu M, Lin C, Guo Y and Tian B: Knockdown of long noncoding RNA GHET1 inhibits cell proliferation and invasion of colorectal cancer. Oncol Res 23: 303-309, 2016.

9. Song X, Cao G, Jing L, Lin S, Wang X, Zhang J, Wang M, Liu W and Lv C: Analysing the relationship between lncRNA and protein-coding gene and the role of lncRNA as ceRNA in pulmonary fibrosis. J Cell Mol Med 18: 991-1003, 2014.

10. Yang F, Xue X, Bi J, Zheng L, Zhi K, Gu Y and Fang G: Long noncoding RNA CCAT1, which could be activated by c-Myc, promotes the progression of gastric carcinoma. J Cancer Res Clin Oncol 139: 437-445, 2013.

11. Nie FQ, Zhu Q, Xu TP,Zou YF, Xie M, Sun M, Xia R and Lu KH: Long non-coding RNA MVIH indicates a poor prognosis for non-small cell lung cancer and promotes cell proliferation and invasion. Tumour Biol 35: 7587-7594, 2014.

12. Wan L, Kong J, Tang J, Wu Y, Xu E, Lai M and Zhang H: HOTAIRM1 as a potential biomarker for diagnosis of colorectal cancer functions the role in the tumour suppressor. J Cell Mol Med 20: 2036-2044, 2016.

13. Guo W, Wang Q, Zhan Y, Chen X, Yu Q, Zhang J, Wang Y, Xu XJ and Zhu L: Transcriptome sequencing uncovers a three-long noncoding RNA signature in predicting breast cancer survival. Sci Rep 6: 27931, 2016.

14. Zhou M, Diao Z, Yue X, Chen Y, Zhao H, Cheng L and Sun J: Construction and analysis of dysregulated lncRNA-associated ceRNA network identified novel lncRNA biomarkers for early diagnosis of human pancreatic cancer. Oncotarget 7 : 56383-56394, 2016. 
15. Tu Z, He D, Deng X, Xiong M, Huang X, Li X, Hao L, Ding Q and Zhang Q: An eight-long non-coding RNA signature as a candidate prognostic biomarker for lung cancer. Oncol Rep 36: 215-222, 2016

16. Liao LM, Sun XY, Liu AW, Wu JB, Cheng XL, Lin JX, Zheng M and Huang L: Low expression of long noncoding XLOC_010588 indicates a poor prognosis and promotes proliferation through upregulation of c-Myc in cervical cancer. Gynecol Oncol 133: 616-623, 2014.

17. Wang L, Zhao Z, Feng W, Ye Z, Dai W, Zhang C, Peng J and Wu K: Long non-coding RNA TUG1 promotes colorectal cancer metastasis via EMT pathway. Oncotarget 7: 51713-51719, 2016.

18. Huang G, Wu X, Li S, Xu X, Zhu H and Chen X: The long noncoding RNA CASC2 functions as a competing endogenous RNA by sponging miR-18a in colorectal cancer. Sci Rep 6: 26524, 2016.

19. Zhou M, Guo M, He D, Wang X, Cui Y, Yang H, Hao D and Sun J: A potential signature of eight long non-coding RNAs predicts survival in patients with non-small cell lung cancer. J Transl Med 13: 231, 2015.

20. Sun Y, Zheng ZP, Li H, Zhang HQ and Ma FQ: ANRIL is associated with the survival rate of patients with colorectal cancer, and affects cell migration and invasion in vitro. Mol Med Rep 14 1714-1720, 2016

21. Yang $\mathrm{P}, \mathrm{Xu} Z \mathrm{Z}$, Chen $\mathrm{T}$ and He ZY: Long noncoding RNA expression profile analysis of colorectal cancer and metastatic lymph node based on microarray data. Onco Targets Ther 9: 2465-2478, 2016.

22. Chen N, Guo D, Xu Q, Yang M, Wang D, Peng M, Ding Y, Wang S and Zhou J: Long non-coding RNA FEZF1-AS1 facilitates cell proliferation and migration in colorectal carcinoma. Oncotarget 7: 11271-11283, 2016.

23. Wu H, Guan S, Sun M, Yu Z, Zhao L, He M, Zhao H, Yao W, Wang E, Jin F, et al: Ano1/TMEM16A overexpression is associated with good prognosis in PR-positive or HER2-negative breast cancer patients following Tamoxifen treatment. PLoS One 10: e0126128, 2015.
24. Xie X, Tang B, Xiao YF, Xie R, Li BS, Dong H, Zhou JY and Yang SM: Long non-coding RNAs in colorectal cancer. Oncotarget 7: 5226-5239, 2016.

25. Yan B, Yao J, Liu JY, Li XM, Wang XQ, Li YJ, Tao ZF, Song YC, Chen $Q$ and Jiang Q: IncRNA-MIAT regulates microvascular dysfunction by functioning as a competing endogenous RNA. Circ Res 116: 1143-1156, 2015.

26. Shen F, Cai WS, Feng Z, Chen JW, Feng JH, Liu QC, Fang YP, Li KP, Xiao HQ, Cao J, et al: Long non-coding RNA SPRY4-IT1 pormotes colorectal cancer metastasis by regulate epithelial-mesenchymal transition. Oncotarget 8: 14479-14486, 2016.

27. Sun J, Ding C, Yang Z, Liu T, Zhang X, Zhao C and Wang J: The long non-coding RNA TUG1 indicates a poor prognosis for colorectal cancer and promotes metastasis by affecting epithelial-mesenchymal transition. J Transl Med 14: 42, 2016.

28. Sunamura N, Ohira T, Kataoka M, Inaoka D, Tanabe H, Nakayama Y, Oshimura M and Kugoh H: Regulation of functional KCNQ1OT1 lncRNA by $\beta$-catenin. Sci Rep 6: 20690, 2016

29. Bian Z, Jin L, Zhang J, Yin Y, Quan C, Hu Y, Feng Y, Liu H, Fei B, Mao Y, et al: 1ncRNA-UCA1 enhances cell proliferation and 5-fluorouracil resistance in colorectal cancer by inhibiting miR-204-5p. Sci Rep 6: 23892, 2016.

30. Yang P, Chen T, Xu Z, Zhu H, Wang J and He Z: Long noncoding RNA GAPLINC promotes invasion in colorectal cancer by targeting SNAI2 through binding with PSF and NONO. Oncotarget 7: 42183-42194, 2016.

(i) (3) This work is licensed under a Creative Commons Attribution-NonCommercial-NoDerivatives 4.0 International (CC BY-NC-ND 4.0) License. 